\title{
Best practice for the use of scenarios for restoration planning
}

Jean Paul Metzger ${ }^{1}$, Karen Esler ${ }^{2}$, Cornelia Krug ${ }^{3,21}$, Melissa Arias ${ }^{1,22}$, Leandro Tambosi ${ }^{4}$, Renato Crouzeilles ${ }^{5,6}$, André Luis Acosta ${ }^{1}$, Pedro HS Brancalion ${ }^{7}$, Francisco D'Albertas ${ }^{1}$, Gabriela Teixeira Duarte ${ }^{8}$, Letícia Couto Garcia ${ }^{9}$, John-Arvid Grytnes ${ }^{10}$, Dagmar Hagen ${ }^{11}$, André Vitor Fleuri Jardim ${ }^{12}$, Chiho Kamiyama ${ }^{13}$, Agnieszka Ewa Latawiec ${ }^{5,14,15,16}$, Ricardo Ribeiro Rodrigues ${ }^{17}$, Patricia GC Ruggiero", Gerd Sparovek $^{18}$, Bernardo Strassburg ${ }^{5,14}$, Antonio Mauro Saraiva ${ }^{19}$ and Carlos Joly ${ }^{20}$

Scenarios are important tools to facilitate the communication among scientists, practitioners, and decision-makers, and, thus to support policy and management decisions. The use of scenarios has an enormous potential to reduce ecosystem restoration costs and to optimize benefits, but this potential remains poorly explored. Here, we recommend and illustrate six best practices to guide the use of scenarios for planning native ecosystem restoration. We argue, first, for a participatory process to consider aspirations of multiple stakeholders along the whole scenario building process, from planning to implementation and review phases. Second, targeted restoration outcomes should be defined by key-actors (those who have direct interests in restoration) and directly involved stakeholders, within a clear socio-environmental context and under a well-defined problem statement, considering a broad range of nature and human benefits that can be derived from ecosystem restoration. Third, methodological choices, such as scenario types, spatial and temporal scales, drivers, restorationrelated variables, and indicators, should be defined according to the multiple desired outcomes. Fourth, we encourage the consideration of the interactions among variables, within a spatially explicit, and temporally dynamic multi-criteria approach. Fifth, analysis and dissemination of scenario results should highlight the trade-offs and synergies among different restoration outcomes, identifying the scenarios that maximize benefits and minimize costs and resistance (i.e. the costeffective and most feasible scenario) for multiple targets. Finally, promoting capacity building, through a wider consultation process including interaction with a broader group of stakeholders, is critical for the successful implementation and review of restoration interventions. Scenarios that support ecosystem restoration should follow an adaptive and iterative process, aiming to continuously improve restoration interventions and outcomes.

\footnotetext{
Addresses

${ }^{1}$ Department of Ecology, Institute of Biosciences, University of São Paulo, Rua do Matão, 321, Travessa 14, 05508-900 São Paulo, SP, Brazil
}

${ }^{2}$ Department of Conservation Ecology and Entomology and Centre for Invasion Biology, Stellenbosch University, Private Bag X1, Matieland 7602, Stellenbosch, South Africa

${ }^{3}$ Laboratoire Ecologie, Systématique et Evolution, UMR 8079 Université Paris-Sud/CNRS/AgroParisTech, Université Paris-Sud XI, Bâtiment 362, 91405 ORSAY Cedex, France

${ }^{4}$ CECS - Centro de Engenharia, Modelagem e Ciências Sociais Aplicadas, Federal University of ABC, Av. dos Estados, 5001, Bairro Santa Terezinha, Santo André, SP, Brazil

${ }^{5}$ International Institute for Sustainability, Estrada Dona Castorina, 124 Horto, 22460-320 Rio de Janeiro, Brazil

${ }^{6}$ Department of Ecology, Federal University of Rio de Janeiro, 68020 Rio de Janeiro, Brazil

${ }^{7}$ Departamento de Ciências Florestais - Esalq/USP, Av. Pádua Dias 11, 13.418-900, Piracicaba, SP, Brazil

${ }^{8}$ Universidade Federal de Minas Gerais, Instituto de Ciências Biológicas, Av. Antonio Carlos, 6627, Pampulha, 31270-901 Belo Horizonte, MG, Brazil

${ }^{9}$ Universidade Federal de Mato Grosso do Sul, Biologia Vegetal, 79070900 Campo Grande, MS, Brazil

${ }^{10}$ Department of Biology, University of Bergen, Postbox 7803, N-5020 Bergen, Norway

${ }^{11}$ Norwegian Institute for Nature Research - NINA, P.O. Box 5685 Sluppen, NO-7485 Trondheim, Norway

${ }^{12}$ Ministério do Meio Ambiente, Secretaria de Biodiversidade, Departamento de Conservação de Ecossistemas, SEPN 505, bloco B, Ed. Marie Prendi Cruz, $4^{\circ}$ andar, sala 402 Asa Norte, 70730542 Brasília, DF, Brazil

${ }^{13}$ United Nations University, Institute for the Advanced Study of Sustainability (UNU-IAS), 5-53-70 Jingumae, Shibuya 150-8925, Japan

${ }^{14}$ Rio Conservation and Sustainability Science Centre, Department of Geography and the Environment, Pontifícia Universidade Católica, 22453900 Rio de Janeiro, Brazil

${ }^{15}$ Institute of Agricultural Engineering and Informatics, Faculty of Production and Power Engineering, University of Agriculture in Kraków, Balicka 116B, 30-149 Kraków, Poland

${ }^{16}$ School of Environmental Science, University of East Anglia, Norwich NR4 7TJ, United Kingdom

${ }^{17}$ Universidade de São Paulo, Escola Superior de Agricultura Luiz de Queiroz, Departamento de Ciências Biológicas, Avenida Pádua Dias n. 11, Centro, Caixa-postal: 9, 13418900 Piracicaba, SP, Brazil ${ }_{18}$ Universidade de São Paulo, Departamento de Ciência do Solo, Esalq/ USP, Av. Pádua Dias 11, 13.418-900, Piracicaba, SP, Brazil

${ }^{19}$ Universidade de São Paulo, Escola Politécnica, Departamento de Engenharia de Computação e Sistemas Digitais, Avenida Professor Luciano Gualberto, Butantã, 05508010 São Paulo, SP, Brazil 
${ }^{20}$ Departamento de Biologia Vegetal, Instituto de Biologia, Universidade Estadual de Campinas, UNICAMP, Campinas, Brazil

Corresponding author: Metzger, Jean Paul (jpm@ib.usp.br)

${ }^{21}$ Current address: URPP Global Change and Biodiversity, Department of Geography, University of Zurich, Winterthurerstrasse 190, CH 8057 Zürich, Switzerland.

\section{Current Opinion in Environmental Sustainability 2017, 29:14-25}

This review comes from a themed issue on Environmental change issues

Edited by Debra Zuppinger-Dingley, Cornelia Krug, Owen Petchey, Michael Schaepman, and Bernhard Schmid

Received 21 July 2017; Revised 17 October 2017; Accepted 24 October 2017

https://doi.org/10.1016/j.cosust.2017.10.004

1877-3435/@ 2017 Elsevier B.V. All rights reserved.

\section{Glossary}

\section{General definitions}

Scenarios: We adopted the definition of IPBES [ $\left.4^{\circ}\right]$, which considers scenarios as 'representations of possible futures for one or more components of the system, particularly for drivers of change in nature and nature's benefits, including alternative policy and management options.'

Models: are simplified representations of real systems. Models can be qualitative or quantitative, and represent some components of the systems and their relationships [ $\left.4^{\circ}\right]$. For ecological restoration, models are particularly important to relate restoration-driven changes in ecosystems structure, with their consequent implications for the functioning of ecosystems, particularly with the provision of ecosystem services.

Ecological restoration: consists of human interventions to assist the recovery of an ecosystem that has been degraded, damaged, or destroyed (sensu SER, [53]). Those actions include the reduction of ongoing degradation processes and an active action to reverse degradation (active restoration action), but can also include actions of halting or avoiding degradation processes, without any other intervention (passive restoration action). Active restoration is a more expensive and labor-intensive action than passive restoration, however passive restoration is only possible if the system is still resilient, and thus can recover by itself (e.g. by natural regeneration processes).

\section{Stakeholders}

Key-actors: are those individuals or institutions that have a direct interest in the restoration process, for example, government agency concerned with enabling policy (signatory to CBD, Aichi targets), landowners. They initiate the process.

Involved stakeholders: are those individuals or institutions who may affect restoration scenarios through their direct actions on restoration sites or through the impacts that scenarios can have on them.
Considered stakeholders: are those individuals and institutions who do not necessarily have an interest or need to participate in the restoration scenarios development, do not have potential to influence the scenarios, but may be directly or indirectly affected by the restoration.

\section{Scenario approach}

Transdisciplinarity: is an interdisciplinary or integrative approach, which crosses disciplinary/academic boundaries, and allows integration of knowledge from academic and non-academic (e.g. practitioners empirical experience or local knowledge) participants to deal with a common research goal [10].

Participatory approach: is an approach in which a range of stakeholders are directly involved in the whole process, from the design to the assessment of scenarios. The approach takes into account different perspectives and issues and adds value to the assessment of synergies and trade-offs.

Adaptive management approach: is an iterative and learning-based management approach, where actions are constantly tested and evaluated, in order to be improved over time. This approach helps to deal with uncertainty and incomplete knowledge in decision-making process, reducing the gap between science and practice [12].

\section{Scenario and model setup}

Outcomes $(Y$-axis): are results, goals or targets to be achieved that address the problem statement according to the perspectives of keyactors and stakeholders. There may be conflicting desired outcomes, but those will provide input into the scenario development process. Input variables: are all variables that can affect expected outcomes, which can include a wide array of direct and indirect human drivers, such as abiotic (e.g. parameter related with relief, climate) and biotic conditions (e.g. regional species pool, local seed banks, seed rain, and germination), landscape structure (e.g. isolation or connectivity to potential source patches, anthropogenic matrix type, fragment size, surrounding habitat amount), time elapsed since restoration, and history of degradation [33].

Problem statement: is the identification of the situation that needs to be solved through ecological restoration, taking into consideration the socio-environmental context.

Socio-environmental context: includes both the biophysical context (i.e. the ecosystem and its bio-physical drivers) as well as the associated societal/social and political actors and institutions. Anthropogenic drivers: are factors or processes associated with human actions or activities that lead to changes in the study systems. Drivers of anthropogenic degradation and restoration will particularly affect biodiversity and the related ecological processes and ecosystem services. Drivers can be either natural (e.g. tornados, landslides, flooding regime) or anthropogenic, but here we focused on anthropogenic direct and indirect drivers.

Anthropogenic direct drivers: are those anthropogenic processes that directly affect ecosystems, and thus depend on a human decision, both related to a degradation process (e.g. native habitat destruction or degradation, introduction of invasive species, construction of infrastructure) or to a restoration action (e.g. reforestation, dam withdrawal). Direct drivers can include: (i) land use change (which relates to the contraction and/or expansion of the areas available for restoration); (ii) land use and land cover degradation (that results from anthropogenic loss of native cover and from other anthropogenic disturbances such as contamination); (iii) disturbance regimes (natural factors that affect the landscape, such as fire, pests, flooding); (iv) invasive species; and, (v) climate change. Anthropogenic indirect drivers: are factors controlled by humans that operate by altering the level or rate of change of one or more direct drivers $\left[4^{\circ}\right]$. They are usually underlying causes of biodiversity and nature's benefit changes, which include institutional and governance

\footnotetext{
$\overline{22}$ Current address: Interdisciplinary Centre for Conservation Science, Department of Zoology, University of Oxford, New Radcliffe House, Oxford OX2 6BW, UK.
} 
structures, as well as socio-political, economic, technological, legal and cultural factors that can affect both degradation processes and restoration actions. Some major indirect drivers of change are: (i) demographic (e.g. human population growth, density, and migration); (ii) economic (e.g. markets, income distribution and demand, incentives, tax benefits, land-use opportunity costs and restoration costs); (iii) science, knowledge (technical or scientific knowledge, including indigenous and local knowledge systems), and technology (physical objects and procedures); (iv) institutions and governance (corporate, governmental, judicial); and (v) cultural (e.g. willingness to restore); (vi) legal (laws affecting restoration commitment).

\section{Introduction}

One of the main environmental challenges of this century is to reverse current anthropogenic landscape degradation trends, acting decisively to restore degraded ecosystems, as recognized by different international commitments, such as the Bonn challenge, the CBD Aichi targets 14 and 15 , or the Initiative $20 \times 20$ in Latin America [1]. However, restoring ecosystems at the spatial and temporal scales proposed by these commitments represents a considerable challenge, which can only be achieved by establishing clear targets, considering the diversity of stakeholders involved and the political, economic, socio-cultural, environmental, legal, and technological contexts of ecosystem restoration. As the resources for restoration are limited and this is a costly activity [2,3], strategic planning is an obligation. The cost-effectiveness, however, will depend on the uncertainties related to the costs of necessary interventions and the potential benefits that can be obtained from restoration actions. Here, scenario comparison can be a key tool for restoration prioritization.

Scenarios were recently defined as representations or storylines of possible futures, including alternative policy or management options $\left[4^{\circ}\right]$. Scenarios are a way to simulate, explore, and compare the possible outcomes of a decision, which makes them an essential decisionmaking tool. They need to be combined with robust models in order to translate the initial conditions defined by each scenario into realistic outcomes $\left[4^{\circ}\right]$.

While scenarios are already used to confront and avoid future degradation processes [5], they are less common in restoration planning, where they can be useful to assess potential impact on biodiversity or ecosystem services (e. g. [6]), and to evaluate the restoration costs (e.g. $[7,8]$ ). Here, we recommend six best practices to guide the use of scenarios for planning native ecosystem restoration. These practices can facilitate, stimulate and optimize restoration actions in the context of the ambitious global restoration commitments planned for the coming decades. An international group of scientists and practitioners, with a wide range of ecosystem restoration experience from around the world, identified these six best practices or principles for the development of more robust restoration scenarios to reduce restoration costs and associated conflicts while optimizing its benefits. The ideal framework to use restoration scenarios should consider a transdisciplinary, participatory, and adaptive management approach, from which our main recommendations of best practices can be derived (Box 1). We also provide a glossary, which should assist scientists and practitioners to more precisely access the set of decision-making tools that scenarios offer to support restoration actions.

\section{Principle \#1 - adoption of a participatory, transdisciplinary, and adaptive management approach}

Ecosystem and landscape restoration aims to conserve biodiversity, safeguard essential ecosystem services for human well-being, and achieve social and economic benefits $[1,9]$. Therefore, restoration scenarios should capture the aspirations of multiple stakeholders, including those who have power to influence restoration initiatives (e.g. government, NGOs, scientists, private companies, community leaders), and also those who are likely to be influenced by the restoration projects (e.g. local communities, landowners).

Stakeholders can have different degrees of involvement in the scenario development process. Key-actors initiate the process and are those individuals or institutions that have a direct interest in the restoration process (e.g. government agency implementing a restoration policy). These key-actors are responsible for identifying the problem statement and socio-environmental context on which to base the scenarios, as well as supporting financially and technically the scenario building process. They also ensure the participation of other parties. Involved stakeholders are individuals and/or institutions recruited by the key-actors because of their potential influence over the scenarios, either directly through their actions on restoration sites or because the scenarios, or the potential outputs of them, directly involve these stakeholders in other ways. Throughout the scenario development process, key-actors and involved stakeholders have to contemplate another group of considered stakeholders. This group may be directly or indirectly affected by the restoration outcomes but do not necessarily have an interest or a need to participate in the restoration scenario development (Figure 1).

Each individual or stakeholder group can have different expectations on restoration outcomes, hence a transdisciplinary [sensu 10] and participatory approach [11] is necessary to have these perspectives correctly represented (see e.g. in Box 2). The group developing the scenarios, particularly key-actors and involved stakeholders, should ensure that the whole range of potential perspectives and interests are represented, aggregating academic and non-academic knowledge. Similarly, they should interactively act on all steps of scenario development, including scenario design, methodological definition, 
Box 1 Proposed framework for building restoration scenarios that should support restoration planning.

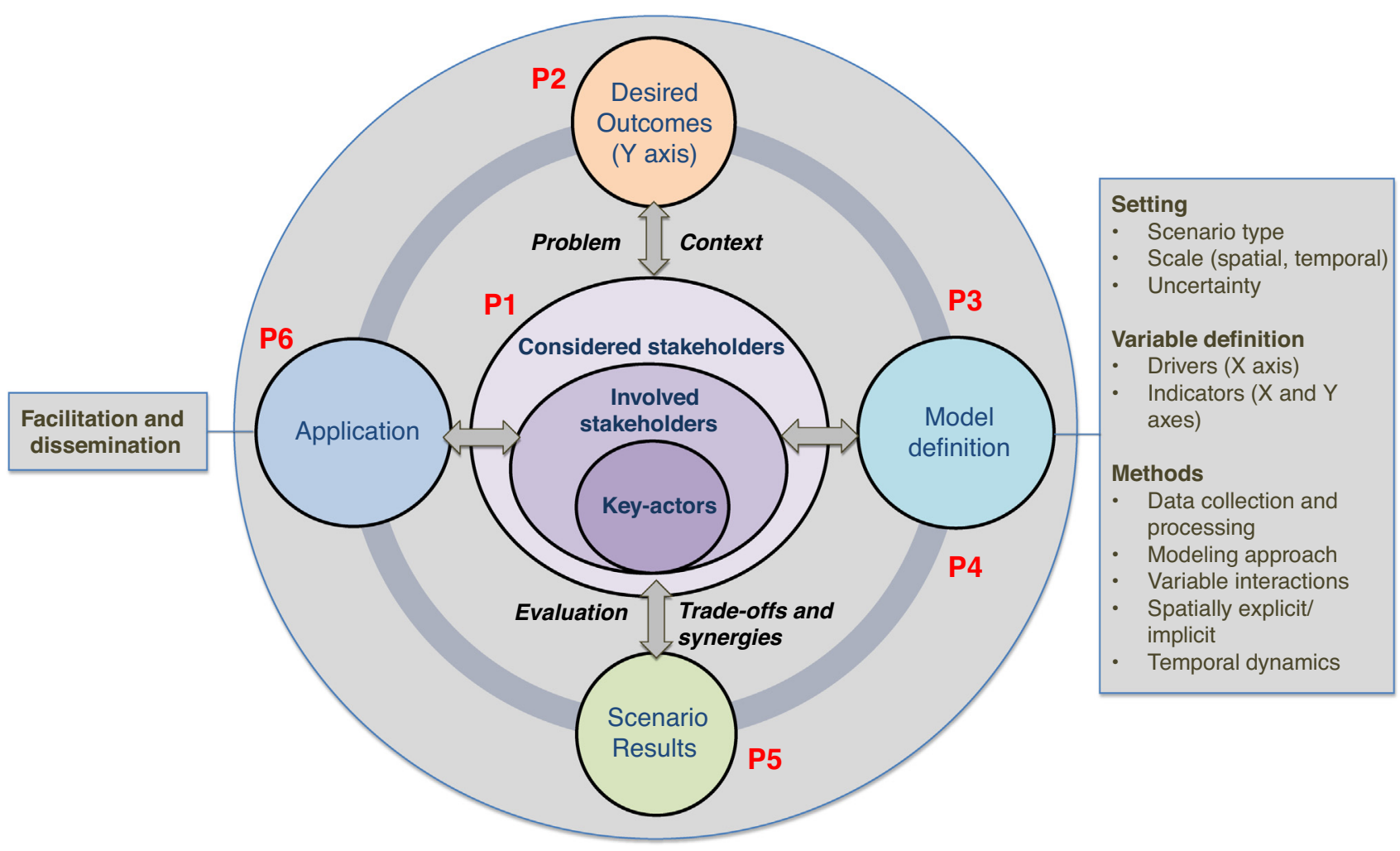

Schematic representation of the six principles (P1-P6) of the proposed framework to guide the use of scenarios and models for restoring native ecosystems.

Principle 1 - The restoration framework begins in the nucleus of the figure with the key-actors. These individuals or institutions have a direct interest in developing a restoration project (e.g. government agency implementing restoration policy). They initiate the restoration scenario building process by identifying the problem statement and the socio-environmental context on which the scenarios will be based. They are also responsible for gathering the financial and technical resources that will be needed for the scenario building process, while also ensuring the participation of other parties. Involved stakeholders have a direct influence on the scenarios, either through their actions or through the impacts that the scenarios can have on them. Therefore, they are recruited by the key-actors to actively participate in the scenario building process. These actors consider the interests of a broader group of considered stakeholders who may be directly or indirectly affected by the restoration process.

Principle 2 - By means of a participatory process, key-actors and involved stakeholders work together to determine the desired outcomes of the scenarios, which represent the range of nature and human benefits of restoration (e.g. enhancing biodiversity or carbon sequestration).

Principles 3 and 4 - The nature of the selected desired outcomes informs the setting, variable definition, and methods that form the basis of the model definition. The setting includes the scenario type (exploratory, target-seeking, retrospective policy evaluation, or policy-screening), scale and level of uncertainty. The variables that will be included into the model comprise the indirect and direct drivers of restoration, as well as the indicators that will be used to measure the effectiveness of the model and of the restoration initiative. Scenario building methods include the modeling approach, data collection and processing, variable interactions, and spatial and temporal specifications.

Principle 5 - The scenario results undergo an evaluation based on the indicators that were specified in the model definition. Through a participatory consultation process, a sub-set of stakeholders assess the trade-offs and synergies of the scenario results in terms of how they work to achieve the desired outcomes. If necessary, they can redefine the desired outcomes and revise the model definition accordingly.

Principle 6 - Once a set of scenario outcomes are agreed upon, the process continues on to the application of the recommendations provided by the scenarios. This last step may include facilitating the incorporation of the results into policy and disseminating the results to a larger audience. As the application of the results from the scenarios takes place (through restoration actions), key-actors may choose to address a new problem statement, restarting the cycle. 


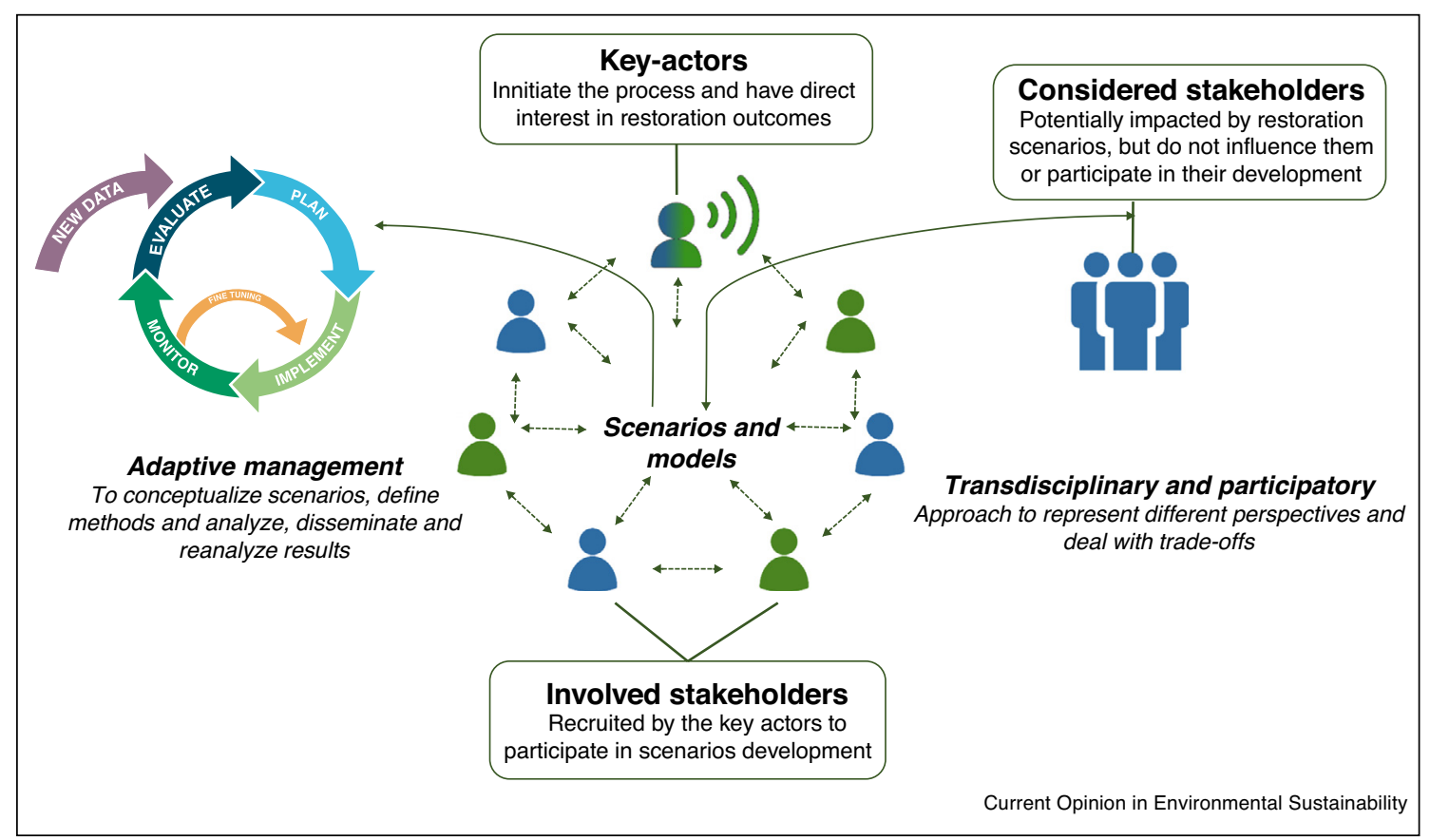

The development of scenarios involves potential stakeholders influencing (green), or being influenced by (blue) restoration, with different roles in the process. A transdisciplinary and participatory approach is employed to harmonize different and sometimes conflicting perspectives on restoration, while adaptive management safeguards scenario functionality in a changing socio-environmental context.

analysis of results, dissemination, and reanalysis, within an adaptive management approach [12].

Taking such a participatory, transdisciplinary, and adaptive management approach is important for two main reasons: it allows the consideration of aspirations and knowledge of multiple stakeholders, while also anticipating constraints for undertaking restoration programs and scenarios. Indeed, the most successful and creative projects involving social-environmental complexity are those where project leaders pursue co-production and co-ownership of knowledge throughout the process $\left[13^{\circ}\right]$. For example, Palacios-Agundez et al. [14] and Convertino et al. [15] showed that developing participatory restoration scenarios that include stakeholder's feedback and preferences generates more realistic scenarios and increases community engagement.

The participatory process, although essential, is not straightforward. Deciding who should be involved in the process is complex (Box 2), as individuals or institutions can have diverse interests. Similar to landscape governance, informal networks, multi-stakeholder coalitions, and/or public-private partnerships are needed to achieve collective, place-bound outcomes [16]. Competencies in decision-making and communication are critical to the process of developing mutual understanding, openness to diverse ideas and progress towards end goals [17].
This complexity requires purposeful and active management and can be time-consuming and expensive [13 $\left.{ }^{\circ}\right]$. The core leaders of the group need to pay careful attention to transparency to encourage participation of those on the periphery of the process and to nurture their involvement through regular meetings [18]. In particular, such leaders have to consider power relationships, as imbalances can derail the entire process $\left[19^{\bullet}, 20\right]$. Being informed about the complexities of group dynamics and organization behavior can help to guide the team-based process [21,22].

A participatory process involving co-production of knowledge is thus needed to generate relevant and reliable restoration scenarios that account for multiple perspectives and sources of information. This is a well-known procedure applied in different management contexts $[23,24]$, but it is still poorly incorporated into restoration planning and even less adopted when scenarios are developed for restoration (but see $[25,26]$ ).

\section{Principle \#2 - multiple desired outcomes should be clearly identified}

A restoration initiative usually involves multiple actors with diverse perspectives, requirements, and desires. Through a participatory process, those aspirations should be clearly translated or represented in the 'expected outcomes' or 'goals' of the restoration scenarios, which can also be considered as the targets to be achieved (see glossary). 
Box 2 Case studies to illustrate the suggested principles for building restoration scenarios

\section{Stakeholder involvement and scenario outcome identification (Principles \#1, 2, 3 and 5)}

Reed et al. [54] and Mitchell et al. [50] provide good examples of how to integrate multiple stakeholders in the restoration scenario building process (Principle \#1). By contrasting two scenarios based on extensifying or intensifying land management in the UK uplands, Reed et al. identified stakeholders by conducting a series of interviews and workshops with interested parties. They then used stakeholder analysis and social network analysis to select a representative and interconnected group of stakeholders. This smaller group was involved in exploring the current and future perceived challenges of the upland system, developing a conceptual model of the main themes and desired outcomes (Principle \#2), constructing scenarios by focusing on the drivers of change within the system and interactions among potential outcomes (Principle \#3), and refining and prioritizing those scenarios based on their trade-offs and synergies (Principle \#5). Similarly, for their case study of the Tasmanian Midlands, an agricultural landscape and grassland biodiversity hotspot, Mitchell et al. engaged government officials, conservationists, rural organizations, landholders and scientists by conducting participatory workshops (Principle \#1). Through these workshops, participants reviewed the historical transformation of the landscape, discussed their desired outcomes, and the likely effects of climate change, other dynamic drivers of change, and governance influencers on the future of the region (Principles \#2 and \#3). This process built upon a prior social-ecological-system analysis of the dynamics affecting native grasslands, and was illustrated through a conceptual model (Principle \#3). On both cases, the workshops ensured that stakeholder's comments were incorporated into the conceptual model and scenario design (Principle \#1).

\section{Methodologies for scenario design (Principle \#3), and benefits of using a spatially explicit approach (Principles \#4 and 5)}

Reed et al. [54] and Birch et al. [6] created their restoration and ecosystem service scenarios through a spatially explicit approach, which provides the unique opportunity to exactly locate areas with restoration potential across large landscapes (Principle \#4). After receiving inputs from involved stakeholders, Reed et al. used spatially explicit computer models to identify the externalities and explore the ecosystem service trade-offs and synergies of two contrasting policy scenarios (Principle \#5). The policy scenarios were on one hand the extensification of land use management in the UK uplands, which refers to restoring land to sequester carbon and to provide habitat for some species, and on the other hand, the intensification of agriculture and livestock production to achieve food security. Their models included variables related to land manager behavior, vegetation dynamics, population dynamics of wildlife species of interest, carbon dynamics, and water quality (Principle \#3). Similarly, in their case study of four different degraded drylands in Latin America, Birch et al. applied a spatially explicit approach to assess the potential impact of restoration on the net value of ecosystem services such as carbon sequestration, timber and non-timber forest products, tourism and livestock production (Principle \#4). The scenarios included business-as-usual state, passive restoration, passive restoration with protection, and active restoration, constructed with a forest dynamics model (Principle \#3). Each of these ecosystem services and their estimated net present values (the difference in value between the business-as-usual scenario and the restoration scenarios) were mapped under each scenario (Principle \#4). A cost-benefit analysis of restoration was conducted by estimating the 'net social benefit of restoration', or the net value of the ecosystem services minus the costs of reforestation, considering the different discount rates involved in land use change (Principle \#3). In addition to showing that restoration leads to increased ecosystem service provision in almost all cases, and that there are marked differences in the cost-effectiveness of the different kinds of restoration scenarios, their results indicate that using a spatially explicit approach can allow areas with the greatest potential benefit per unit cost to be prioritized for conservation planning (Principle \#4). Both studies conclude that using a spatially explicit approach allows identification of the exact location of trade-offs and complementarities among desired outputs in order to minimize externalities and create a winwin situation for the environment, climate change, and for the livelihood of local landowners (Principle \#5).

\section{Analyzing outcome trade-offs and synergies (Principle \#5) and communicating results effectively (Principle \#6)}

Mitchell et al. [50] and Reed et al. [54] make use of story lines and narratives to construct and communicate their restoration scenarios effectively (Principle \#6). After their workshops and stakeholder consultations, Mitchell et al. applied a systems-based strategy to consider critical uncertainties within the drivers of change on the Tasmanian Midlands system dynamics. They created a quadrant matrix of scenarios comprising the possible combinations of these uncertainties. A smaller group of researchers (here considered as key-actors and involved stakeholders) was then able to refine scenario narratives based on scientific expert consultation. The scenarios varied on the basis of farmer profitability and social and human capital, ranging from agricultural loss and rural decline to sustainable and profitable agriculture. These narratives were then brought back to the community so that stakeholders could understand how their decisions would affect their environment (Principle \#6). In a similar fashion, Reed et al. used story lines and narratives to define their extensification or intensification policy scenarios in the UK uplands (Principle \#6). The narratives were communicated to stakeholders by film, which facilitated the integration of information from a wide range of sources, including local and scientific knowledge, and gave public relevance to the issue while also providing rigorous evidence (Principle \#6). The films illustrated and communicated those narratives in a way that was easy for people from different backgrounds and education to understand and endorse. For both studies, the narratives allowed stakeholders to identify opportunities for biodiversity conservation and potential sources of financial support to incentivize local stakeholders to pursue win-win opportunities whenever possible (Principle \#5).

Desired outcomes should be simply and clearly illustrated, for example, if quantifiable, as the $Y$-axis or the response variable of the scenario graphs (i.e. conservation outcomes and/or nature's contributions to people), which can be projected into the future by each scenario through models $\left[4^{\circ}\right]$. Such outcomes can be diverse, including matters such as habitat structure (e.g. biomass, vegetation stratification), provision of ecosystem services (e.g. water supply, soil stabilization), presence or abundance of a particular species (e.g. threatened species, or species providing relevant ecosystem services), richness or diversity of a taxonomic group, or control of invasive species.
However, it is important to realize that these desired outcomes may not fully occur even if the projected restoration scenario is implemented, as there will always be uncertainties associated with the modeling process as well as with the trajectory that a habitat under restoration might take.

To appropriately define potential outcomes, key-actors and involved stakeholders need first to identify a common 'problem statement' and define the socio-environmental context. For example, in South Africa's Cape Floristic Region, invasive alien trees threatened not only 
indigenous biodiversity but also water provision, livestock production, and livelihoods [27]. The socio-environmental context related to budget limitations, management capacity, and landowner attitudes constrained decisive actions for invasive species control, and needed to be considered in the scenario development $\left[28^{\bullet}, 29\right]$. In a South American example, the conservation of two mammal species was considered in a context of limited funds. Alternative scenarios were thus considered by maximizing habitat availability and biogeographical representation, while minimizing land acquisition costs to restore 12 million ha of Atlantic Forest [7]. Through this process of problem statement and social-environmental context definition, conservation and economic interests of different stakeholders should be taken into account (see e.g. in Box 2).

Following the social process outlined above will ensure credibility (technical evidence or premises are adequate), saliency (findings are relevant to decision-makers), and legitimacy (all views and beliefs are considered and impartially tackled), key ingredients for an effective scenario development process [30].

\section{Principle \#3 - definition of methodological choices according to expected outcomes}

The development of scenarios involves multiple methodological choices regarding the type of scenarios, the selection of direct and indirect drivers influencing restoration, as well as other restoration-related variables and indicators. Those choices are not always obvious, and for this reason they need to be based, first of all, on the desired outcomes provided by the involved and considered stakeholders and on the type of restoration required.

First, it is critical to determine the appropriate type of scenario. There are four types of scenarios according to the typology proposed by the Intergovernmental Science-Policy Platform on Biodiversity and Ecosystem Services - [ $\left.\left.4^{\circ}\right]\right)$ : (i) Exploratory scenarios examine different plausible futures based on past trends and in possible (e.g. positive/negative, optimistic/pessimistic) storylines or future trends of some variables, usually indirect drivers such as socio-political, economic, or technological factors; (ii) Target-seeking scenarios define targets of $Y$-axis outcomes (e.g. nature or nature's benefits to people) to be achieved in the future, and then consider different initial conditions and scenarios to attain those targets; (iii) Policyscreening scenarios compare different ways to apply a particular policy (such as restoration) based on their impact on required outcomes ( $Y$-axis); and (iv) Retrospective policy evaluations compare the projected outcomes obtained from scenarios applied in the past with actual achievements, analyzing the reasons for differences between expected and realized outcomes. All these scenarios can be applied to restoration, depending on the restoration phase: exploratory scenarios are useful for agenda setting, target-seeking and policy-screening ones are adequate for an intervention phase, while retrospective policy evaluations are suitable for a review phase $\left[4^{\circ}\right]$.

Second, involved and considered stakeholders must identify key direct and indirect drivers (see glossary) that may influence the restoration process, taking into account the desired outcomes (Figure 2). For example, rural-urban migration is a main indirect driver for large-scale forest recovery in some Latin American countries, and thus should be considered in large-scale restoration planning, both at the exploratory (exploratory scenarios) and intervention stages (target-seeking or policy-screening scenarios). Similarly, sustainable agricultural intensification (direct driver) is a mechanism that can avoid agricultural expansion and consequently spare land for restoration $\left[31^{\circ}\right]$; hence it is an important factor to consider in scenario development. For instance, Bohnet et al. [32] developed a landscape toolkit with which stakeholders create and evaluate spatially-explicit land use and management change scenarios. This process offers more transparency and highlights possible conflicts of interest among different stakeholders.

Third, there are specific restoration-related variables that should be considered when scenarios are modeled [33], such as biotic (e.g. persistence of soil seed banks, dispersing fauna) and abiotic variables (e.g. soil quality, slope, precipitation, rainfall seasonality, landscape structure parameters). These variables can affect the local and landscape resilience of the study system, modulating the system's capacity to intrinsically recover $\left[34^{\circ}\right]$, and defining when a passive restoration strategy is possible, or inversely, when an active restoration is required [35]. The spatial and temporal scales of restoration initiatives as well as data uncertainty and availability are likely to drive the choice of restoration-related variables (Figure 2). Additionally, variables should be chosen in a participatory manner, considering the perspectives of key-actors and other stakeholders (as shown in the general framework figure in Box 2), who possess the technical expertise and on-the-ground knowledge regarding restoration drivers and their future trajectories [36].

Fourth, as multiple drivers and restoration-related variables may be involved in planning restoration, a multicriteria approach that compares scenarios with different targets is critical. Egoh et al. [37], for example, explore scenarios to achieve a European Union $15 \%$ restoration target (target-seeking scenario), considering both endangered species conservation and ecosystem service provision. To develop the models, they compared sets of scenarios with a different combination of targets to better explore the most suitable combination of outcomes. Restoration scenarios also need to be based on the identification of specific, observable, and measurable indicators that will be used to assess the suitability of scenarios in terms of whether they reach the desired outcomes or 


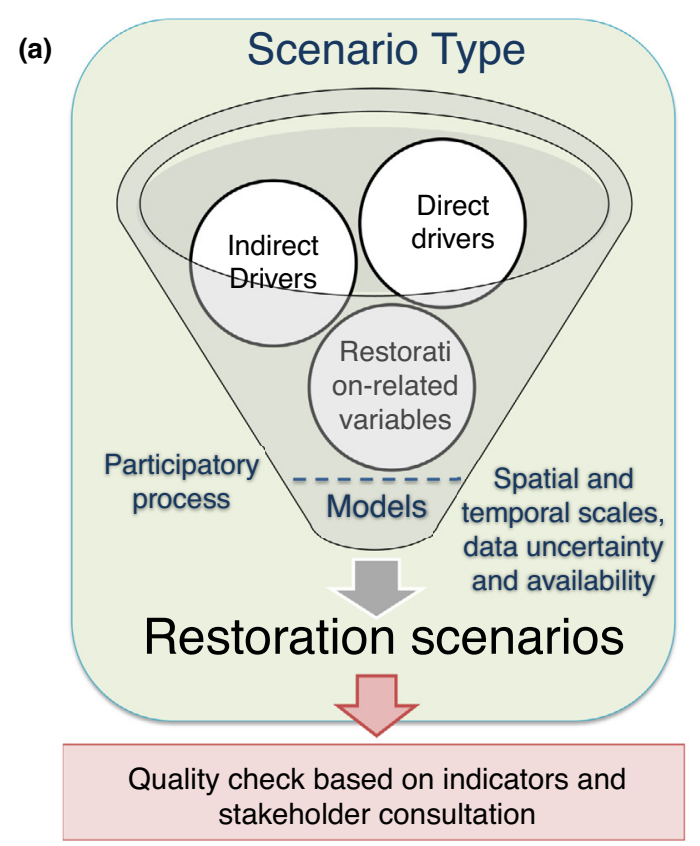

(b)

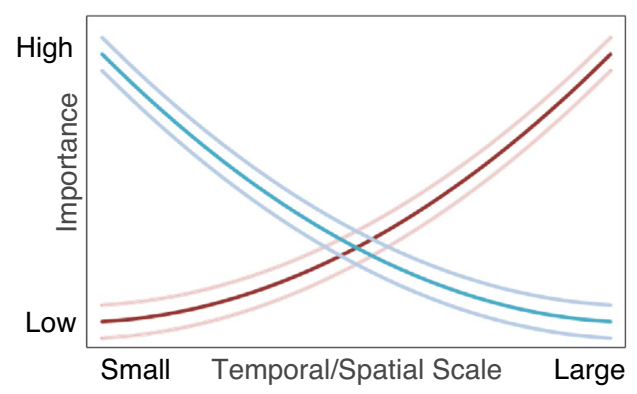

(c)

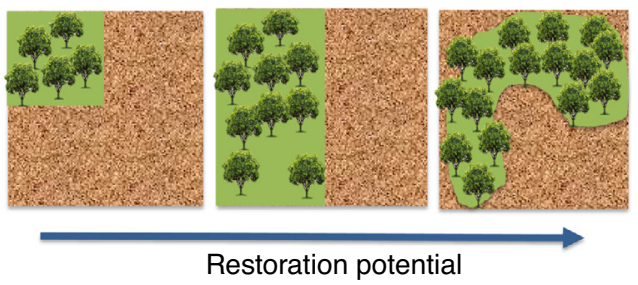

Current Opinion in Environmental Sustainability

(a) The type of scenario (from IPBES, $\left[4^{\circ}\right]$ ) will inform the selection of direct and indirect drivers and restoration-related variables, by means of a participatory process, and considering spatial and temporal scales as well as data uncertainty and availability. These variables will then interact with each other based on their given parameters. The chosen model filters those interactions to generate different restoration scenarios. Once the scenarios are built, the results should be evaluated based on pre-established indicators and in consultation with multiple stakeholders. (b) Drivers and restoration-related variables can be more or less important depending on their temporal and spatial scale. For example, climate change can be very important at a large temporal and spatial scale, but not necessarily for a short-term plot level restoration project (red line). Similarly, an abiotic restoration-related variable such as soil quality can be crucial when planning restoration at a small scale, but less relevant for a large landscape with multiple soil types and varying soil fertility (blue-line). Such changing relevance must be considered when choosing drivers and restoration-related variables. (c) Adopting a spatially explicit approach is important to model restoration scenarios. In particular, the spatial configuration of existing forest patches and new restoration areas can strongly influence the speed, type, and cost of restoration, while also determining functional connectivity.

targets, as well as the cost-effectiveness of the restoration initiative [7].

\section{Principle \#4 - scenarios should be spatially explicit, temporally dynamic and should consider outcome interactions}

Once the scenario type, drivers, and restoration-related variables are identified, the restoration project can move forward to the modeling stage. At this stage, the participants of the restoration project have to make a series of decisions that will form the basis of the models that will be used to compare the different scenarios.

First, they have to decide whether the model will be spatially explicit (e.g. does the spatial arrangement of the landscape matters to the restoration process being modeled?), implicit (e.g. does the spatial location of each habitat patch need to be specified in the model?), or non-spatial (e.g. do theoretical models reveal the interaction among variables, without any reference to space?). Since restoration outcomes are clearly affected by the surrounding landscape and the functioning of the latter is affected by restoration areas $\left[34^{\circ}, 38\right]$, we strongly advocate for a spatially explicit approach (see Box 2 and Figure 2). This approach optimizes results and enables planning a restoration scenario that simultaneously minimizes costs (for example, properly allocating areas for passive restoration) and identifies priority areas for active restoration (e.g. with an increase in biodiversity status and ecosystem services provision). In this context, for example, Perry and Enright [39] compared outcomes from spatially explicit and implicit models applied to the same system (using the same initial parameters), supporting the notion that spatially explicit models are better for restoration applications (see also [40] and Box 2 for more information).

Second, a wide range of methods can be used for modeling scenarios, including mental maps, conceptual models, systematic conservation planning, and mathematical models. For example, both Tambosi et al. [41] and Crouzeilles et al. [7] approached the effects of habitat 
availability on the identification of priority areas for restoration in the Atlantic Forest. However, while the former ranked landscapes based on their contribution to increase connectivity, the latter used a systematic conservation planning approach to solve a mathematical problem statement. Solutions to restoration prioritization modeling regarding mathematical problem statements tend to be more complex, but are more informative to decision makers as they deal with specific targets and costs [42].

Third, it is important to identify and set parameters for the interactions and feedbacks among the chosen drivers and restoration-related variables, focusing on temporal dynamics. For example, the potential for natural forest regeneration depends on the amount of forest in the surrounding landscape (among other restoration-related variables), which can change over the time that the restoration takes place [L. Tambosi, $\mathrm{PhD}$ thesis, University of São Paulo, 2014; [43]]. The interactions between variables through time will determine scenario trajectories, which in turn can significantly affect the duration and outcome of restoration initiatives, as well as their costs, demanding adaptive management. We argue here that a dynamic approach is necessary to correctly plan and evaluate restoration outcomes.

Finally, the parameters that define variable interactions and their temporal dynamics must be identified through rigorous data collection, experimentation, modeling, and/ or expert knowledge. Data can be collected from multiple sources, such as literature reviews of past restoration studies or other reports on the trends or behavior of variables. Parameterization of variables for the model(s) will also benefit significantly from the inclusion of expert knowledge, which can come from the key-actors, involved and/or considered stakeholders, or from other restoration experts (Box 2).

We note that the development of restoration scenarios requires multiple data types and sources, analyses, and models, which is only possible by integrating different software tools (see supplementary material).

\section{Principle \#5 - analysis and dissemination should highlight outcome trade-offs and synergies, promoting an iterative process of scenario construction}

As soon as scenario results are available, an adequate strategy for analysis and dissemination among stakeholders should be initiated. Such strategy should clearly outline the steps that will be taken to verify the adequacy of the results, followed by a detailed analysis and discussion of the synergies and trade-offs that were identified by the scenarios. For example, by comparing land use scenarios, Butler et al. [44] assessed trade-offs between food and fibre production and water quality regulation, affecting differently farmers and fishermen in The Great Barrier Reef, Australia. A broad stakeholder consultation of scenarios' results may help to identify and solve such kind of potential conflicts.

The sub-set of stakeholders who participated in the model definition should also engage in the analysis of the scenario and model outputs (see for e.g. Box 2). These parties should compare the outcomes for each scenario and assess whether the scenario outcomes adequately represent how the indirect and direct drivers interact with each other and with other restoration-related variables. In a multi-criteria approach, scenarios can be compared, through cost-effective or cost-benefit analysis, that is, identifying the scenario that results in the highest targeted benefits per unit of costs. It is also important to compare trade-offs between scenarios, since the most cost-effective situation may not reach the minimum desired outcomes. The choice of spatial and temporal scales, as well as the level of uncertainty given data availability, should also be explicit in the results. Additionally, these stakeholders should evaluate whether the resulting outcomes are compatible with the initial targets of the restoration project, and verify whether the restoration drivers and variables that were chosen in the model definition reflected those objectives properly. If there are discrepancies, those inputs need to be modified, or alternative inputs should be added. These decisions should be done in consultation with the parties involved, in an iterative or adaptive management approach, as previously mentioned.

When analyzing the final results, a close examination of the trade-offs and synergies among the resulting scenarios is necessary, especially when a great number of variables and criteria are adopted in the scenario construction. This can be done by plotting the different scenario results against each other, using, for example, spider diagrams or portfolio maps to identify trade-offs and win-win solutions $[45,46]$, or by applying a spatially explicit analysis to map trade-offs and win-win situations $[46,47]$. The examination of these trade-offs and synergies allows identifying the scenarios that maximize synergies and minimize trade-offs for all targets and all stakeholder expectations. It might well be the case that no single scenario reaches all objectives, or inversely, there could be certain scenarios that impact negatively on the interests of a particular stakeholder group. In these cases, new scenarios that reflect different sets of viewpoints might be needed, following an adaptive management approach.

To resolve potential conflict among stakeholders, scenario selection requires repeated stakeholder consultation, in particular when intervention scenarios are considered (see Bohnet et al. [32] for an example of stakeholders building and selecting scenarios). If conflicts exist, it might be necessary to perform this step with the different key-actors and stakeholder groups separately, before moving on to joint consultations that include all stakeholders. In these consultations, the results of the scenario 
analysis should be presented in a way that is tailored to each stakeholder group(s), that is, 'translated' appropriately [48]. The feedback provided from the stakeholder groups, and the additional knowledge received, is then incorporated into a set of new or modified scenarios. This iterative process allows for the selection of scenarios that are acceptable for the different actors involved in the exercise and leads to a set of feasible scenarios that reflect the actors' perceptions, practical experience, and viewpoints [25].

\section{Principle \#6 - interactive, face-to-face meetings coupled with field days can optimize communication, capacity building, and application of scenarios' insights} The first step towards successful application of the scenarios developed is their appropriate dissemination to key-actors and stakeholders, including a description of their indirect and direct drivers, and how they impact on the selected restoration-related variables of interest. Communicating the process and key outcomes to a wider audience can facilitate buy-in from a broader stakeholder community. Communication can take on a multitude of forms, depending on the audience to be reached, and the desired level of interaction and stakeholder engagement. Workshops allow time for interventions and face-to-face discussions among experts and key-actors, and facilitate reflection on the potential impacts of the scenario outcomes, which can, ultimately, lead to improved decision-making [49]. Coupling workshops with excursions or field days makes the results even more tangible. Exhibitions, 'road shows', and lecture series are designed to address a broad audience, while scientific publications and policy briefs target a very specific audience. Social media can serve as an excellent outreach tool, with webinars and Massive Open Online Courses allowing for direct interaction with the audience. More interactive formats can also be used to promote capacity building and to provide the targeted audience with the necessary skills to understand the results and apply the outcomes of the different scenarios (see for e.g. Box 2).

Promoting capacity building also facilitates the incorporation of the results and outcomes of the scenarios into policy. Dialogue workshops between decision-makers, policy-makers, and experts maximize the knowledge transfer and uptake of results, while workshops with practitioners and managers facilitate the conversion of the scenario results into practical restoration applications [50]. These workshops and dialogues enable the formulation of implementation plans and, using the variables of interest, the development of monitoring plans. Regular monitoring and reporting of results can then be used to verify the scenario outputs and results [51], and to adapt the parameterization of the models and readjustment of scenarios. The iterative interaction between practitioners, key-actors, and experts enables true adaptive management and formulation of adequate legislation and incentive mechanisms. Hence, direct interactions with the group of people that have the power of influencing restoration and those mostly affected by its outcomes are key to achieving a successful community of practice and successful restoration programs.

\section{Final remarks}

The use of scenario modeling to improve restoration planning is not yet fully explored, but is critical to guide costeffective restoration interventions at the unprecedented scales promoted by emerging global restoration commitments. Restoration programs now have to progress beyond the simplistic definition of a given number of hectares to restore, and start considering the inherent challenges to address the expected trade-offs arising from the combination of multiple restoration goals in areas already disputed by other land uses and interests $\left[52^{\circ}\right]$. To fully realize the potential of scenario modeling for restoration, we advocate for the use of the guidelines presented here. We reinforce the need to incorporate a transdisciplinary, participatory, and adaptive management approach to restoration scenario building. During this scenario building process it is essential that key-actors and other stakeholders negotiate their interests and select desired outcomes, participate actively in methodological choices, discuss the synergies and trade-offs among different outcomes, communicate results with a broader audience, and engage in an adaptive cycle that leads to improved restoration scenarios, and from this allow for more successful restoration projects. We also encourage the application of a spatially explicit and dynamic multi-criteria modeling approach, at adequate scales, with a well-developed problem statement, and the use of multiple iterative and face-to-face communication and capacity building activities to successfully achieve restoration outcomes. Most of these suggestions are quite general and well-known in other management practices, but they can facilitate the use of scenarios in the context of ecosystem restoration. The use of scenario tools has to go beyond their more common usage to avoid degradation processes. A more widespread application of scenarios to guide restoration planning, implementation, and monitoring in large-scale programs is possible.

\section{Conflicts of interest}

There is no conflict of interest.

\section{Appendix A. Supplementary data}

Supplementary material related to this article can be found, in the online version, at https://doi.org/10.1016/j. cosust.2017.10.004.

\section{References and recommended reading}

Papers of particular interest, published within the period of review, have been highlighted as:

- of special interest

1. Chazdon RL, Brancalion PHS, Lamb D, Laestadius L, Calmon M, Kumar C: A policy-driven knowledge agenda for global forest and landscape restoration. Conserv Lett 2017:10. 
2. Holl KD, Howarth RB: Paying for restoration. Restor Ecol 2000:8.

3. De Groot RS, Blignaut J, Van Der Ploeg S, Aronson J, Elmqvist T, Farley J: Benefits of investing in ecosystem restoration. Conserv Biol 2013:27.

4. IPBES: Methodological Assessment of Scenarios and Models of - Biodiversity and Ecosystem Services. Secretariat of the Intergovernmental Platform for Biodiversity and Ecosystem Services; 2016.

Recent and updated methodological assessment of the use of scenarios and models for biodiversity and ecosystem services.

5. Carpenter SR, Booth EG, Gillon S, Kucharik CJ, Loheide S, Mase AS, Motew M, Qiu J, Rissman AR, Seifert J et al.: Plausible futures of a social-ecological system: Yahara watershed, Wisconsin, USA. Ecol Soc 2015:20.

6. Birch JC, Newton AC, Aquino CA, Cantarello E, Echeverria C, Kitzberger T, Schiappacasse I, Garavito NT: Cost-effectiveness of dryland forest restoration evaluated by spatial analysis of ecosystem services [Internet]. Proc Natl Acad Sci 2010, 107:21925-21930.

7. Crouzeilles R, Beyer HL, Mills M, Grelle CEV, Possingham HP: Incorporating habitat availability into systematic planning for restoration: a species-specific approach for Atlantic Forest mammals. Divers Distrib 2015:21.

8. Dorrough J, Vesk PA, Moll J: Integrating ecological uncertainty and farm-scale economics when planning restoration. $J$ App Ecol 2008:45.

9. Mansourian S, Stanturf JA, Derkyi MAA, Engel VL: Forest landscape restoration: increasing the positive impacts of forest restoration or simply the area under tree cover? Restor Ecol 2017:25.

10. Tress G, Tress B, Fry G: Clarifying integrative research concepts in landscape ecology. Landsc Ecol 2005:20.

11. Kok MTJ, Kok K, Peterson GD, Hill R, Agard J, Carpenter SR: Biodiversity and ecosystem services require IPBES to take novel approach to scenarios. Sustain Sci 2017:12.

12. Allen CR, Fontaine JJ, Pope KL, Garmestani AS: Adaptive management for a turbulent future. J Environ Manage 2011:92.

13. Turner BL, Esler KJ, Bridgewater P, Tewksbury J, Sitas JN,

- Abrahams B, Chapin FS, Chowdhury RR, Christie P, Diaz S et al.: Socio-Environmental Systems (SES) research: what have we learned and how can we use this information in future research programs. Curr Opin Environ Sustain 2016:19.

Provides key lessons for integrated socio-environmental science (SES), drawing from successful SES interdisciplinary projects and programs.

14. Palacios-Agundez I, Onaindia M, Potschin M, Tratalos JA, Madariaga I, Haines-Young R: Relevance for decision making of spatially explicit, participatory scenarios for ecosystem services in an area of a high current demand [Internet]. Environ Sci Policy 2015, 54:199-209.

15. Convertino M, Foran CM, Keisler JM, Scarlett L, LoSchiavo A, Kiker GA, Linkov I: Enhanced adaptive management: integrating decision analysis, scenario analysis and environmental modeling for the Everglades [Internet]. Sci Rep 2013, 3:2922.

16. Van Oosten C: Forest landscape restoration: who decides?. A governance approach to forest landscape restoration. Nat Conserv 2013:11.

17. McGreavy B, Lindenfeld L, Bieluch KH, Silka L, Leahy J, Zoellick B: Communication and sustainability science teams as complex systems. Ecol Soc 2015:20.

18. Cundill G, Roux DJ, Parker JN: Nurturing communities of practice for transdisciplinary research. Ecol Soc 2015:20.

19. Sitas N, Reyers B, Cundill G, Prozesky HE, Nel JL, Esler KJ:

- Fostering collaboration for knowledge and action in disaster management in South Africa. Curr Opin Environ Sustain 2016:19.

An analysis of a multiple stakeholder-engagement process, identifying obstacles and enabling factors in the process fo knowledge exchange and knowledge co-production.
20. Kunseler E-M, Tuinstra W: Navigating the authority paradox: practising objectivity in environmental expertise. Environ Sci Policy 2017:67.

21. Hall KL, Vogel AL, Stipelman BA, Stokols D, Morgan G, Gehlert S: A four-phase model of transdisciplinary team-based research: goals, team processes, and strategies. Transl Behav Med 2012:2.

22. Kunseler E-M, Tuinstra W, Vasileiadou E, Petersen AC: The reflective futures practitioner: balancing salience, credibility and legitimacy in generating foresight knowledge with stakeholders. Futures 2015:66.

23. Reed MS: Stakeholder participation for environmental management: a literature review. Biol Conserv 2008:141

24. Newig J, Fritsch O: Environmental governance: participatory, multi-level - and effective? Environ Policy Gov 2009:19.

25. Etienne M, Le Page C, Cohen M: A step-by-step approach to building land management scenarios based on multiple viewpoints on multi-agent system simulations. JASSS 2003:6

26. Lazos-Chavero E, Zinda J, Bennett-Curry A, Balvanera P, Bloomfield G, Lindell C, Negra C: Stakeholders and tropical reforestation: challenges, trade-offs, and strategies in dynamic environments. Biotropica 2016, 48:900-914.

27. van Wilgen BW, Reyers B, Le Maitre DC, Richardson DM, Schonegevel L: A biome-scale assessment of the impact of invasive alien plants on ecosystem services in South Africa. $J$ Environ Manage 2008:89.

28. Roura-Pascual N, Richardson DM, Chapman RA, Hichert T,

- Krug RM: Managing biological invasions: charting courses to desirable futures in the Cape Floristic Region. Reg Environ Chang 2011:11.

Introduces a scenario planning method, and illustrates how different view points and management activities are considered to define the scenarios.

29. Urgenson LS, Prozesky HE, Esler KJ: Stakeholder perceptions of an ecosystem services approach to clearing invasive alien plants on private land. Ecol Soc 2013:18.

30. Cash DW, Clark WC, Alcock F, Dickson NM, Eckley N, Guston DH, Jäger J, Mitchell RB: Knowledge systems for sustainable development. Proc Natl Acad Sci U S A 2003:100.

31. Latawiec AE, Strassburg BBN, Brancalion PHS, Rodrigues RR,

- Gardner T: Creating space for large-scale restoration in tropical agricultural landscapes. Front Ecol Environ 2015:13.

Highlights the trade-offs and synergies that need to be taken into consideration in large-scale restoration projects.

32. Bohnet IC, Roebeling PC, Williams KJ, Holzworth D, van Grieken ME, Pert PL, Kroon FJ, Westcott DA, Brodie J: Landscapes toolkit: an integrated modelling framework to assist stakeholders in exploring options for sustainable landscape development. Landsc Ecol 2011, 26:1179-1198.

33. Crouzeilles R, Curran M, Ferreira MS, Lindenmayer DB, Grelle CEV, Rey Benayas JM: A global meta-analysis on the ecological drivers of forest restoration success. Nat Commun 2016:7.

34. Metzger JP, Brancalion PHS: Landscape ecology and

- restoration processes. In Foundations of Restoration Ecology. Edited by Margaret A, Palmer JBZ, DAF. Island Press; 2016:90120.

Comprehensive textbook chapter about the interface and synergies between landscape ecology and restoration ecology.

35. Holl KD, Aide TM: When and where to actively restore ecosystems? For Ecol Manage 2011:261.

36. Kaltenborn BP, Linnell JDC, Thomassen J, Lindhjem H: Complacency or resilience? Perceptions of environmental and social change in Lofoten and Vesterålen in northern Norway. Ocean Coast Manag 2017:138.

37. Egoh BN, Paracchini ML, Zulian G, Schägner JP, Bidoglio G Exploring restoration options for habitats, species and ecosystem services in the European Union. J Appl Ecol 2014 51:899-908. 
38. Leite MDS, Tambosi LR, Romitelli I, Metzger JP: Landscape ecology perspective in restoration projects for biodiversity conservation: a review. Nat Conserv 2013:11.

39. Perry GLW, Enright NJ: Contrasting outcomes of spatially implicit and spatially explicit models of vegetation dynamics in a forest-shrubland mosaic. Ecol Modell 2007, 207:327-338.

40. Birch JC, Newton AC, Aquino CA, Cantarello E, Echeverría C Kitzberger T, Schiappacasse I, Garavito NT: Cost-effectiveness of dryland forest restoration evaluated by spatial analysis of ecosystem services. Proc Natl Acad Sci U S A 2010:107.

41. Tambosi LR, Martensen AC, Ribeiro MC, Metzger JP: A framework to optimize biodiversity restoration efforts based on habitat amount and landscape connectivity. Restor Ecol 2014:22.

42. Kareksela S, Moilanen A, Tuominen S, Kotiaho JS: Use of inverse spatial conservation prioritization to avoid biological diversity loss outside protected areas. Conserv Biol 2013:27.

43. Wilson KA, Lulow M, Burger J, Fang Y-C, Andersen C, Olson D, O'Connell M, Mcbride MF: Optimal restoration: accounting for space, time and uncertainty. J Appl Ecol 2011:48.

44. Butler JRA, Wong GY, Metcalfe DJ, Honzák M, Pert PL, Rao N, van Grieken ME, Lawson T, Bruce C, Kroon FJ et al: An analysis of trade-offs between multiple ecosystem services and stakeholders linked to land use and water quality management in the Great Barrier Reef, Australia [Internet] Agric Ecosyst Environ 2013, 180:176-191.

45. Guerry AD, Ruckelshaus MH, Arkema KK, Bernhardt JR, Guannel G, Kim C-K, Marsik M, Papenfus M, Toft JE, Verutes G et al:: Modeling benefits from nature: using ecosystem services to inform coastal and marine spatial planning. Int $J$ Biodivers Sci Ecosyst Serv Manag 2012:8

46. Crookes DJ, Blignaut JN, de Wit MP, Esler KJ, Le Maitre DC, Milton SJ, Mitchell SA, Cloete J, de Abreu P, Fourie H et al.: System dynamic modelling to assess economic viability and risk trade-offs for ecological restoration in South Africa. $J$ Environ Manage 2013:120.

47. Roura-Pascual N, Krug RM, Richardson DM, Hui C: Spatiallyexplicit sensitivity analysis for conservation management: exploring the influence of decisions in invasive alien plant management. Divers Distrib 2010:16.

48. Hulme PE: Bridging the knowing-doing gap: know-who, knowwhat, know-why, know-how and know-when. J Appl Ecol 2014:51.

49. Evans LS, Hicks CC, Fidelman P, Tobin RC, Perry AL: Future scenarios as a research tool: investigating climate change impacts, adaptation options and outcomes for the Great Barrier Reef, Australia. Hum Ecol 2013:41.

50. Mitchell M, Lockwood M, Moore SA, Clement S: Building systems-based scenario narratives for novel biodiversity futures in an agricultural landscape. Landsc Urban Plan 2016 145:45-56.

51. Hagen D, Evju M: Using short-term monitoring data to achieve goals in a large-scale restoration. Ecol Soc 2013:18.

52. Brancalion PHS, Chazdon RL: Beyond hectares: four principles

- to guide reforestation in the context of tropical forest and landscape restoration. Restor Ecol 2017 http://dx.doi.org/ 10.1111/rec.12519.

Introduces principles and guidelines for forest and landscape restoration to ensure synergies between biodiversity conservation, climate mitigation and improvement of local livelihoods.

53. Clewell A, Aronson J, Winterhalder K: The SER International primer on ecological restoration [Internet]. Ecol Restor 2004 2:206-207.

54. Reed MS, Hubacek K, Bonn A, Burt TP, Holden J, Stringer LC, Beharry-Borg N, Buckmaster S, Chapman D, Chapman PJ et al.: Anticipating and managing future trade-offs and complementarities between ecosystem services. Ecol Soc 2013:18. 